\title{
UNIVERSIDADE BRASILEIRA SEGUNDO O INQUÉRITO DE 1928: ENSINO, PESQUISA E EXTENSÃO
}

\author{
José Carlos Souza Araújo
}

UNIUBE

\section{RESUMO}

O objeto deste é estruturar uma análise das "theses desenvolvidas pela Comissão Organizadora do Inquerito promovido pela 'A.B.E. [Associação Brasileira de Educação], realizado en 1928 a respeito do problema universitario brasileiro. As referidas 'theses', em um total de sete, foram desenvolvidas por intelectuais do Rio de Janeiro. O conteúdo de tais 'theses' se ocupa com o modelo de universidade a ser construído, pela recusa a modelos externos ou à sua adaptação, assim como a recusa a um modelo único para o país. A universidade brasileira deveria constituir-se em torno da cultura brasileira, e revelar-se como uma 'usina mental', com o objetivo de pensar o Brasil e, ao mesmo tempo, despertar sua consciencia de nacionalidade. As críticas à falta de organização da educação brasileira são comuns. Tratava-se de repor em novos parâmetros a pedagogia universitária, na qual professores e alunos se apresentavam ao norteamento da Comissão da A.B.E. como figuras-chave. As referências à aula, aos métodos, ao livro-texto, à situação financeira do professorado, à sua necessária profissionalização, à sua remuneração, à sua formação, à manipulação do ensino superior pelos profissionais liberais, à ação centralizadora da educação por parte do Governo Federal são faces de uma mesma moeda.

Palavras-chave: Associação Brasileira de Educação (A.B.E.); Universidade; Inquérito de 1928; Pesquisa.

\section{THE BRASILILAN UNIVERSITY ACCORDING TO THE SURVEY OF 1928: TEACHING, RESEARCH AND EXTENSION}

\begin{abstract}
The objective of this survey is to organize and analyze the "thesis developed by the Organizing Committee of Enquiry, sponsored by A.B.E. ( Brazilian Association of Education), accomplished in the year of 1928, about the problem on Brazilian universities. The referred theses, in a total of seven, were developed by scholars of Rio de Janeiro. The content about the thesis takes as a model the approaches on the external or the adaptation, as well as the refuses a single model for the country. The Brazilian University should build around the Brazilian culture, and reveals itself as a 'usina mental', with the objective of thinking about Brazil, and, at the same time, awakening the consciousness of nationality. The criticism and the lack of organization of the Brazilian education are frequent. It was expected to deal with recovering of the university pedagogics, in which teachers and students presented themselves to directions of $\mathrm{ABE}$, as a main character. References to class methods, textbook, the financial situation of teachers, to their required professional, the financial situation of the staff in regard to their necessary professionalization, to their salary, to their formation, to the manipulation of the Higher Education by liberal professionals, to the centralizing action of education produced by the government are aspects of the same coin.
\end{abstract}

Keywords: Brazilian Association of Education (ABE); University; Survey 1928; Survey. 
O objeto deste é estruturar uma análise das "theses desenvolvidas pela Comissão Organizadora do Inquerito promovido pela 'A.B.E.' [Associação Brasileira de Educação]."'. Tratava-se, através dele, de enfrentar o problema universitário brasileiro.

Aliás, este é o título da publicação, ocorrida em 1929, acompanhada do seguinte subtítulo: "Inquérito promovido pela Secretaria de Ensino Technico e Superior da Associação Brasileira de Educação [A.B.E.]". Tal inquérito foi, na verdade, resultante de uma decisão ocorrida por ocasião da Segunda Conferência Nacional de Educação, promovida pela própria A.B.E., cuja realização deu-se em Belo Horizonte, MG, entre 04 e 11 de novembro de 1928.

A A.B.E., fundada em 16 de outubro de 1924, uma instância de iniciativa cidadã, promoveu a participação da sociedade civil a respeito dos problemas educacionais, em oposição e em detrimento da centralização por parte do Estado, autoritariamente cioso em orientar a discussão e o encaminhamento político-educacional. Tal entidade "[...] veio a ter importância fundamental para o direcionamento das mudanças que se fizeram na segunda metade da década de 1920 e, principalmente, na primeira metade da década seguinte" (Dicionário Histórico-Biográfico Brasileiro, 1930-1983, p. 229).

Sinonimicamente, inquérito pode-se traduzir por averiguação minuciosa, pesquisa, investigação. Nessa direção, o termo mais adequado para qualificar o Inquérito de 1928 é investigação, baseada na elaboração de um questionário que se orientava em torno de sete questões:

I- Que typo universitario adoptar no Brasil? Deve ser único? Que funcções deverão caber às universidades brasileiras?

II- Não convirá, para solução do nosso problema universitário, aproveitar os elementos existentes, como Observatorios, Museus, Bibliotecas, etc., provendo á sua articulação no conjuncto universitário?

III- Não é oportuno realizar, dentro do regimen universitário, uma obra conscientemente nacionalizadora do espírito da nossa mocidade?

IV- Não seria de todo útil aos governos estaduaes auxiliem ao governo federal na organização universitária?

V- Não convém estabelecer mais íntimo contacto entre o professor e o alumno? Como conseguil-o?

VI- Não convém a adopção, onde possível do livro texto (systema norteamericano) em substituição gradual ao ensino oral?

VII- É satisfactória a situação financeira do professorado universitário? Não se impõem medidas reparadoras? (O PROBLEMA UNIVERSITÁRIO BRASILEIRO, 1929, p. 337-343)

Quando da realização do Inquérito de 1928, existiam apenas duas universidades no Brasil: a Universidade do Rio de Janeiro (atual UFRJ) e a Universidade de Minas Gerais (atual UFMG), a primeira criada em 07 de setembro de 1920 pelo Governo Federal, através do Decreto ${ }^{\circ} 14.343$, e a segunda, no dia 07 de setembro de 1927 por meio da Lei Estadual $n^{\circ} 956$.

As políticas educacionais estaduais em torno da escola primária e secundária conferiam à educação brasileira um andamento relativamente lento, se se leva em conta o alto déficit educacional de então, além do crescimento demográfico brasileiro que passou de 14.333.915 habitantes em 1890, para 30.645.065 em 1930. Ressalte-se que tal 
crescimento foi incentivado pela imigração estrangeira, responsável em $15 \%$ pelo aumento populacional, e pelo alto coeficiente de natalidade em torno de $2,91 \%$, segundo o censo de 1920.

Em referência aos anos de 1920, e quando foi responsável pelo Inquérito de 1926, a serviço do jornal $O$ Estado de São Paulo, Fernando de Azevedo assim se posicionou relativamente à educação superior: "[...] a falha capital que se apontou, foi a ausência de Universidades ou a tremenda deficiência de instituições de altos estudos e de pesquisas" (Azevedo, 1960, p. 22).

\section{Visão geral sobre a obra 'O problema universitário brasileiro'}

Em seu conteúdo, tal obra apresenta duas partes, a primeira que acolhe as referidas "Theses desenvolvidas pela Commissão Organizadora do Inquérito promovido pela 'A.B.E.'", as quais somam sete; e a segunda parte reúne as "Respostas ao Inquérito", num total de quarenta e três depoimentos, os quais representam posicionamentos de inquiridos de sete Estados: Rio de Janeiro, São Paulo, Minas Gerais, Rio Grande do Sul, Pernambuco, Bahia e Paraná. Somando-se às sete 'Theses' da Comissão, orientadoras do Inquérito, a obra reúne 50 depoimentos sobre a questão universitária brasileira.

Nesse sentido, as referidas 'theses' abrangem posições de sete intelectuais, cujos títulos de suas comunicações traduzem os eixos temáticos que nortearam a estruturação do Inquérito de 1928:

- F. Labouriau. O problema universitário brasileiro, p. 7-13;

- E. Roquette Pinto. Organização universitária, p. 14-18;

- Vicente Licínio Cardoso. Creação de focos de brasilidade, p. 19-25;

- Raul Leitão da Cunha. A crise actual do ensino, no Brasil-seus factores e seus aspectos, p. 26-31;

- Ignácio M. Azevedo Amaral. O professor e o alumno, p. 32-44;

- Domingos Cunha. A situação financeira do professorado universitário; suas deficiências, p. 45-51;

- Levi Carneiro. Legitimidade e conveniência do concurso estadual para a solução do problema universitário, p. 52-67.

\section{As 'theses' desenvolvidas pela Comissão Organizadora do Inquérito de 1928}

Inicialmente, cabe esclarecer quem são os autores das 'Theses'. Pela ordem em que estão dispostas, visa-se aqui informar a trajetória de cada um deles desde as suas datas e lugares de nascimento, além de sua trajetória de formação e de exercícios profissionais, pelo menos até o momento do Inquérito. Assim:

- Ferdinando Labouriau (1893-1928) nasceu em Niterói, RJ, formou-se na Escola Politécnica do Rio de Janeiro, na qual se tornou professor concursado aos 24 anos. Foi Presidente da A.B.E. em 1926 e 1927 em mandatos trimestrais, bem como foi dirigente da Comissão que promoveu o Inquérito de 1928. 
- Edgard Roquette-Pinto (1884-1954) nasceu no Rio de Janeiro, e formou-se em 1905 pela Faculdade de Medicina do Rio de Janeiro, porém fez carreira no campo da Antropologia. Além de professor, foi diretor do Museu Nacional nos anos 1920.

- Vicente Licínio Cardoso (1890-1931) nasceu no Rio de Janeiro, e tornou-se engenheiro civil pela Escola Politécnica do Rio de Janeiro em 1912. Em 1926, tornou-se professor da mesma Escola, através de concurso.

- Raul Leitão da Cunha (1881-1947), nascido no Rio de Janeiro, formou-se em 1903 pela Faculdade de Medicina do Rio de Janeiro, com a qual teve vínculos profissionais desde 1905.

- Ignácio M. Azevedo Amaral (1889-1950) foi professor de balística e artilharia na Escola Naval. Foi professor da Escola Normal do Distrito Federal e catedrático da Escola Politécnica. Foi reitor da Universidade do Brasil.

- Domingos Cunha foi professor (outras informações não foram localizadas no atual estágio da pesquisa).

- Levi Carneiro (1882-1971) nasceu em Niterói, RJ, e foi formado pela Faculdade de Ciências Jurídicas e Sociais do Rio de Janeiro em 1903. Ocupou a presidência do Instituto dos Advogados do Brasil entre 1921 e 1929.

Ainda que incompletamente, dentre os sete, seis estão ligados à formação superior, dois pela Faculdade de Medicina do Rio de Janeiro, três pela Escola Politécnica do Rio de Janeiro, e um pela Faculdade de Ciências Jurídicas e Sociais do Rio de Janeiro.

Com a preocupação de sistematizar a exposição, bem como a problematização posta em questão pelo Inquérito de 1928, alguns temas podem ser encontrados nas 'theses' desenvolvidas pela Comissão Organizadora do Inquérito de 1928: críticas às reformas educativas; fuga aos modelos de universidade; afirmação do regionalismo; a brasilidade como uma questão universitária nacional; a pedagogia universitária: o professor, o aluno e as suas relações, e o ensino, a pesquisa e a extensão. Para efeito de exposição, foram escolhidos os três últimos temas.

\section{a) A brasilidade, uma questão universitária nacional}

Dentre as 'theses' vinculadas a tal categoria temática, é destacável o posicionamento de Vicente Licínio Cardoso em Creação de focos de brasilidade. A epígrafe de tal comunicação caracteriza o seu norteamento geral:

A Universidade brasileira, tal como a concebem as consciencias políticas eminentemente brasílicas, isto é a usina mental onde pudessem ser pensados e postos em equação os problemas magnos da nacionalidade, continua, apezar da fertilidade das reformas, a ser, em sua inexistência, o expoente máximo da bastardia espiritual da cultura de nossas elites. (1929, p. 19)

Ou seja, a sua crítica assegura que a concepção de universidade, que veicula nos meios políticos, é representante de uma degradação moral das elites. Trata-se, a seu ver, de equacionar os problemas nacionais através da universidade que viesse a se constituir como 
uma 'usina mental', isto é, que viesse a transformar a matéria-prima (ou seja, os problemas nacionais) em produtos com algum acabamento.

Para isso, concorreriam os professores universitários, pois deveriam eles se constituir como "[...] professores de brasilidade, formadores em summa da consciencia brasilica da própria mocidade" (Cardoso, 1929, p. 19). Por isso mesmo, a sua concepção é de que "[...] as universidades são, essencialmente, grandes templos cívicos da pátria" (Cardoso, 1929, p. 20).

Na mesma direção, a da universidade contribuir predominantemente para elaborar a consciência nacional, situa-se a posição de Labouriau: "focos de cultura e de brasilidade: eis o que devem ser as nossas universidades" (1929, p. 9).

A perspectiva nacional também está presente na reflexão que segue:

Que é do lado da cultura espiritual que o Estado se deve voltar: e acreditamos que não basta ensinar o povo a lêr. A utilisação de todos os nossos recursos dependerá de maior nível cultural. Parece-nos que haverá no Brasil mais justiça, mais disciplina, mais riqueza, mais força quando organizarmos seriamente os nossos gymnasios, onde se lucram os alicerces do saber e as nossas universidades onde se deverão apurar as nossas melhores intelligencias. (Roquette-Pinto, 1929, p. 16)

Em suma, sua posição afirma o movimento universitário como propulsor da alta cultura nacional, à medida que discipline a mocidade (ibidem, 1929, p. 18). Sustenta que as universidades populares, nas quais devera haver cursos livres de tudo, para todos, e devem ser assumidas pelas 'universidades reaes' (ibidem, 1929, p. 18).

E arremata com uma reflexão sobre as elites: "Quando as nossas elites sentirem em plenitude as responsabilidades de nossos destinos históricos, estará formada a consciência do Brasil" (Ibidem, p. 23). Num tom altamente nacionalista, evoca a superfície geográfica brasileira, o papel dos portugueses que conquistaram todo esse território, a vida nos trópicos, a fusão de culturas, a opulência da natureza brasileira.

Disso tudo, espera Cardoso "a eclosão da própria nacionalidade" (p. 24). Como se observa, trata-se de congregar as faculdades oficiais e livres com um só objetivo, o da nacionalização da cultura: “[...] nacionalisação de nossos programmas de estudos; de nossos próprios professores universitários" (Ibidem, p. 24).

\section{b) A pedagogia universitária: o professor e o aluno como intersubjetividade}

Criar o espírito universitário passa necessariamente pelos professores e pelos alunos, como deixa entrever Labouriau: "É uma mentalidade a desenvolver. O primeiro passo, que se pode considerar preparatório, é prender mais estreitamente ao ensino os alunos e os professores. Depois, desenvolver o interesse público pelas questões geraes" (1929, p. 8).

Para Roquette-Pinto, conforme citação feita anteriormente, o nível cultural mais elevado trará benefícios de várias ordens ao Brasil: trata-se de burilar os alunos desde os 'gymnasios', pois nestes estão os alicerces do saber. Trata-se de organizá-los, bem como às universidades, estas como lugares de se apurar "as nossas melhores inteligências" (1929, p.16).

Segundo Vicente Licínio Cardoso, os professores universitários deveriam ser especialmente "professores de brasilidade, formadores em summa da consciencia brasilica 
da própria mocidade" (1929, p. 19). Mas reclamava ele da qualificação do professor, cabendo-lhe a seguinte orientação:

[...] dever primacial do professor - raramente até agora seguido - fazer o alummno, alem das disciplinas profissionaes de seu curso, habituar-se desde cedo a 'pensar o Brasil', formula essa de todo expressiva com que a geração actual synthetisou a necessidade do equacionamento, passado e futuro, dos complexos problemas brasileiros. (Cardoso, 1929, p. 19)

Para outro depoente, como vimos, defendia “[...] unidade da educação pela uniformidade de instrucção" (Cunha, 1929b, p. 26). Para ele, o ensino superior brasileiro apresentava, então, deficiências muito importantes em vista da pedagogia universitária. E a aula é a instância em foco:

Quase todos nossos acadêmicos são visitantes efêmeros da Escola, principalmente porque nela não encontram atractivos interessantes, nem local apropriado para estudos e meditação. Assim, desobrigados da tarefa massadoira de assistir à aula, abandonam, apressados, o sitio em que deveriam permanecer as melhores horas do dia. (Cunha, 1929b, p. 30)

Além da evidente observação de que a aula não se constituía como central ao processo pedagógico, a crítica também se faz às aulas existentes:

[...] ainda perdura o sistema de darem-se aulas teóricas e práticas intercaladas e medidas a relógio, só porque tal forma de proceder serve para algumas cadeiras. Sobrecarregam-se professores com trabalho, ameúde exaustivo, por força de grande número de estudantes, unicamente porque, para as cadeiras exclusivamente teóricas esse facto não tem importância maior. (Cunha, 1929b, p. 30)

Chamando a atenção a respeito da importância dos cursos normais para a formação do professor, reflete outro inquirido que o docente "[...] deve possuir qualidades resultantes de um conjuncto de condições phisicas, moraes e intellectuaes [...]" (Amaral, 1929, p. 34), as quais não se resolvem apenas por informações vagas ou pelas provas de admissão aos cargos de ensino. Além disso, advoga que:

Somente por uma longa e cuidadosa observação systematicamente orientada durante um período razoável, poder-se-á ajuizar da aptidão pessoal para o magistério, como somente por um trabalho educativo, gradualmente realisado, conseguir-se-á desenvolver e orientar as aptidões naturaes de cada um para o mais perfeito para o exercício da actividade profissional em que se resume o professorado. (Amaral, 1929, p. 35)

Sobre o aluno, advoga o estudo de sua personalidade pelos professores, em vista da diagnose vocacional e da necessária adaptação a cada caso, em termos individuais. "É impossível educar e instruir com o melhor aproveitamento sem o conhecimento das condições pessoaes de cada alumno [...]" (Amaral, 1929, p. 35). Para isso, defendia a redução ao mínimo da quantidade de alunos confiados a cada professor, uma vez que seria irrealizável o ensino individual.

Entretanto, enfatizava que ao professor devia caber não somente uma atuação de um modo coletivo, mas também uma atuação individual. Caberá ao professor, ainda, presidir aos estudos, observar as dificuldades dos alunos, orientar os estudos, enfim caberá a ele realizar uma obra de educação intelectual. "O íntimo contacto entre o professor e o 
alumno, indispensável à efficiência da obra educativa, não deve se limitar à convivência nas salas de aulas e de estudo, nos gabinetes e laboratórios" (Ibidem, 1929, p. 36-37). Trata-se de estreitá-las também através das associações acadêmicas, de modo que sejam destinadas "[...] a systematizar a cooperação de professores e alumnos na obra educativa [...]" (Ibidem, 1929, p. 37).

Para isso, além da remuneração adequada, defende que

O professor, mesmo nos cursos universitários, não pode ter por funcção exclusiva fazer um limitado numero de prelecções. A sua missão exige uma consagração integral do seu tempo e de suas energias, não só ao seu estudo próprio, que poderia ser feito em seu gabinete, mas à educação e ao ensino de seus discípulos, o que só deverá ser feito em sua escola. (Amaral, 1929, p. 37)

\section{c) O ensino, a pesquisa e a extensão}

Em atenção ao ensino, trata-se de escolher o "systema mais conveniente para a transmissão desses conhecimentos" (Amaral, 1929, p. 38). Refere-se a duas maneiras de fazê-lo: a) o ensino pelo livro, afirmado como prática pedagógica norte-americana; b) o ensino oral, através de preleções, conferências, demonstrações, experiências, aulas práticas em laboratórios e em gabinetes.

Relativamente ao ensino pelo livro, discorre que se trata do denominado método da redescoberta. Ao professor cabe aparelhar o aluno para a descoberta, ou seja, estão aqui estabelecidas concretamente as diretrizes escolanovistas:

O objectivo pedagógico norte-americano pode ser definido como consistindo em libertar pouco a pouco o pensamento, o sentimento e a actividade do educando de toda espécie de tutela, reduzindo gradualmente o papel do professor em proveito da iniciativa e da responsabilidade do discípulo. (Amaral, 1929, p. 39)

No tocante à exposição oral, afirma-a devotada ao ensino prático dos alunos em vista dos trabalhos, das experiências e das pesquisas. Azevedo Amaral opta por defender o ensino pelo livro, porque este traz um plano, "permite uma melhor metodização do ensino" (Amaral, 1929, 40); além disso, o conteúdo organizado e presente no livro poderá ser disposto à "[...] vehiculação de princípios em que se deve fundar a política educacional da nacionalidade" (Ibidem, 1929, p. 40).

Em suma,

[...] o complemento natural das considerações que vêm sendo expendidas a respeito do professor e o alumno, consistirá num esboço da organização escolar mais conveniente para a execução das idéias expostas relativamente à educação e ao ensino, e para apuração do aproveitamento dos alumnos nos cursos realisados. (Amaral, 1929, p. 42-43)

Em seguida, suas considerações se fazem em torno da necessária organização dos conteúdos e das diferentes disciplinas, as quais devem contar com turmas pequenas de alunos. As aulas deverão ter objetos definidos; os alunos deverão estar disponíveis a orientações pelos professores durante o tempo de estudos em gabinetes e em laboratórios para a realização de suas pesquisas e experiências. 
A extensão universitária destina-se ao desenvolvimento do interesse público pelas questões gerais: trata-se de "[...] levar ao conhecimento do público o que se vem fazendo no mundo technico, no campo da sciencia, no domínio das artes e das letras: os trabalhos que estão em ordem do dia, as directivas que se lhes dão. Impõem-se para tanto, cursos e conferências públicas, de vulgarização e de alta cultura" (Labouriau, 1929, p. 8).

E ainda, é inerente às universidades a realização da extensão ao lado do ensino, sob a pena de estarem traindo a si mesmas como organização. Nessa direção, o próprio Labouriau (1929) lista um conjunto de cursos e conferências desenvolvidos pela A.B.E. em 1926 (com 54 conferências), em 1927 (com 68), mencionando que para o ano de 1928 já estavam em curso 90 conferências. E conclui: "O que a Associação Brasileira de Educação vem conseguindo realizar sem apoio official e sem recursos materiaes, deverá com maior efficiencia ser feito pelas nossas universidades, desde que estas sejam mais do que meras promessas" (Labouriau, 1929, p. 11).

Em referência à pesquisa, o mesmo depoente a defende explicitamente: “[...] impõe-se em nossas futuras universidades a creação de instituições destinadas a desenvolver os estudos de pesquiza scientifica. Com a sua ausência, perde a organização universitária uma de suas maiores razões de ser" (Labouriau, 1929, p. 11-12).

O próprio Labouriau insere em sua comunicação a seguinte posição: “As Universidades e a pesquiza scientifica": "[...] além do ensino de sciencia feita, a de formar pesquizadores, em todos os ramos dos conhecimentos humanos" (Labouriau, 1929, p. 12); defendia ele também que os pesquisadores deveriam ter obrigações didáticas reduzidas, que se assegurassem de recursos materiais, tais como laboratórios, observatórios, bibliotecas especializadas, periódicos para a divulgação de seus trabalhos, aparelhamento necessário às explorações geográficas, geológicas e mineralógicas, biológicas, etnográficas; além disso, também é mencionada a defesa do tempo integral de trabalho com uma remuneração suficiente.

O horizonte de Labouriau é o progresso: "Só assim poderão preencher a sua alta finalidade, como dynamicos factores de progresso que devem ser, e não burocráticos mecanismos, emperrados" (Ibidem, 1929, p. 13).

\section{Conclusão}

Em termos de síntese, as 'Theses' da referida Comissão da A.B.E. se ocupam, em perspectivas diversas, com o modelo de universidade a ser construído, com a repulsa a modelos externos ou à sua adaptação, bem como com a rejeição a um modelo único para o país. Defendia-se a construção de uma universidade brasileira, que não resultasse de uma agregação de faculdades, que expressasse um espírito universitário assentado na articulação entre o ensino, a extensão e os estudos e as pesquisas.

Tal direção recusava o ensino fundado somente em ciência feita, defendia a formação de pesquisadores, e que tivessem uma carga horária didática reduzida, bem como recursos materiais para o desenvolvimento da pesquisa. Enfim, a universidade devia manifestar-se pelos interesses públicos gerais, bem como constituir-se em foco de cultura e de brasilidade, além de constituir como uma 'usina mental'. Fazia-se mister pensar o Brasil através da universidade. Ela também deverá ser uma instância para dar identidade à consciência de nacionalidade. 
As críticas à falta de organização da educação brasileira são comuns, em muitos aspectos, àquelas presentes no Inquérito de 1926, realizado por Fernando de Azevedo. Tratava-se de repor em novos parâmetros a pedagogia universitária, na qual professores e alunos se apresentavam ao norteamento da Comissão da A.B.E. como figuras-chave. As referências à aula, aos métodos, ao livro-texto, à situação financeira do professorado, à sua necessária profissionalização, à sua remuneração, à sua formação, à manipulação do ensino superior pelos profissionais liberais, à ação centralizadora da educação por parte do Governo Federal são faces de uma mesma moeda.

As reações à Universidade do Rio de Janeiro de então, criada em 1920, e à recémcriada Universidade de Minas Gerais, em 1927, ocupam o cenário de tais discussões, pelo menos em seus bastidores. Estava emergindo concretamente a idéia de que a pesquisa devesse constituir a vida universitária. A pesquisa seria um parâmetro, que deveria ser tomado como um norte.

As palavras de Labouriau constituiram-se numa síntese de tais Theses, e, na verdade, um programa para o futuro em torno do ensino, da pesquisa e da extensão universitário:

Somente com as directrizes eschematicamente apontadas: - organização moldável às variadas condições dos nossos grandes centros; mais estreita prisão ao ensino, dos alumnos e professores; cursos livres de vulgarização e de alta cultura, parallelamente aos cursos technicos seriados; pesquizas scientificas em todos os ramos do conhecimento humano; desenvolvimento da cultura artística, literária e philosofica - é que poderão merecer as nossas organizações universitárias o pomposo titulo que até hoje têm usado. (1929, p. 12-13)

\section{Referências}

AMARAL, Ignácio M. Azevedo. O professor e o alumno. In O problema universitário brasileiro: Inquérito promovido pela Secção de Ensino Technico e Superior da Associação Brasileira de Educação. Rio de Janeiro: Encadernadora, 1929, p. 32-44.

AZEVEDO, Fernando de. A educação na encruzilhada: problemas e discussões. $2^{\mathrm{a}}$. edição, São Paulo: Melhoramentos, 1960.

CARDOSO, Vicente Licínio. Creação de focos de brasilidade. In O problema universitário brasileiro: Inquérito promovido pela Secção de Ensino Technico e Superior da Associação Brasileira de Educação. Rio de Janeiro: Encadernadora, 1929, p. 19-25.

CARNEIRO, Levi. Legitimidade e conveniência do concurso estadual para a solução do problema universitário. In $O$ problema universitário brasileiro: Inquérito promovido pela Secção de Ensino Technico e Superior da Associação Brasileira de Educação. Rio de Janeiro: Encadernadora, 1929, p. 52-67.

CUNHA, Domingos. A situação financeira do professorado universitário; suas deficiências. In O problema universitário brasileiro: Inquérito promovido pela Secção de 
Ensino Technico e Superior da Associação Brasileira de Educação. Rio de Janeiro: Encadernadora, 1929, p. 45-51.

CUNHA, Raul Leitão da. A crise actual do ensino, no Brasil - seus factores e seus aspectos. In O problema universitário brasileiro: Inquérito promovido pela Secção de Ensino Technico e Superior da Associação Brasileira de Educação. Rio de Janeiro: Encadernadora, 1929, p. 26-31.

DICIONÁRIO HISTÓRICO-BIOGRÁFICO BRASILEIRO, 1930-1983. Rio de Janeiro: Editora Forense-Universitária: FGV/CPDOC: Financiadora de Estudos e Projetos-FINEP, 1984.

LABOURIAU, F. O problema universitário brasileiro. In O problema universitário brasileiro: Inquérito promovido pela Secção de Ensino Technico e Superior da Associação Brasileira de Educação. Rio de Janeiro: Encadernadora, 1929, p. 7-13.

O PROBLEMA UNIVERSITÁRIO BRASILEIRO: Inquérito promovido pela Secção de Ensino Technico e Superior da Associação Brasileira de Educação. Rio de Janeiro: Encadernadora, 1929.

ROQUETTE-PINTO, Edgard. Organização universitária. In O problema universitário brasileiro: Inquérito promovido pela Secção de Ensino Technico e Superior da Associação Brasileira de Educação. Rio de Janeiro: Encadernadora, 1929, p. 14-18. 